\title{
PEMEROLEHAN KOSAKATA DASAR NOMINA \\ BAHASA INDONESIA ANAK USIA 3 TAHUN \\ (STUDI KASUS DI KELURAHAN LEBAK BANDUNG KOTA JAMBI)
}

\author{
Andi Hani ${ }^{1}$, Ade Rahima ${ }^{2}$, Abdoel Gafar ${ }^{3}$ \\ Program Studi Pendidikan Bahasa dan Sastra Indonesia, \\ Fakultas Keguruan dan Ilmu Pendidikan, Universitas Batanghari, \\ Jambi
}

andihani21@gmail.com

ade_rahima@yahoo.com

gafar3r@yahoo.co.id

\begin{abstract}
This research is aimed at identifying the acquisition of basic noun vocabulary of Indonesian language on 3 years old childern in Lebak Bandung area. Thsi research is qualitative descriptive. In conducting the data, the question answer technique is used by showing pictures to 3 years old children in Kelurahan Lebak Bandung. Based on the result of the research, it can be found that 3 years old children are able to pronounce one to six vocabulary which categorize good and less good with their own words.
\end{abstract}

Keywords : Acquisition, Indonesian Language Noun, 3 Years Old Children

\footnotetext{
${ }^{1}$ Mahasiswa Program Studi Pendidikan Bahasa dan Sastra Indonesia, Fakultas Keguruan dan Ilmu Pendidikan, Universitas Batanghari, Jambi

${ }^{2}$ Dosen Program Studi Pendidikan Bahasa dan Sastra Indonesia, Fakultas Keguruan dan Ilmu Pendidikan, Universitas Batanghari, Jambi

${ }^{3}$ Dosen Program Studi Pendidikan Bahasa dan Sastra Indonesia, Fakultas Keguruan dan Ilmu Pendidikan, Universitas Batanghari, Jambi
} 


\section{PENDAHULUAN}

Manusia membutuhkan bahasa untuk mengekspresikan diri, beradaptasi dan berkomunikasi dengan lingkungan sosialnya secara lisan maupun tulisan. Bahasa sebagai alat komunikasi dalam bentuk lisan ialah yang dihasilkan oleh alat ucap manusia. Ujaran yang berupa sistem bunyi memiliki makna yang dapat dipahami oleh penutur maupun menanggap tuturnya. Masyarakat Indonesia mempergunakan tidak hanya satu bahasa, melainkan lebih dua bahasa yaitu bahasa ibu (b1) dan bahasa Indonesia (b2) sehingga penutur bahasa di Indonesia merupakan tempat persentuhan antara bahasa ibu dan bahasa Indonesia.

Menurut Kiparsky (dalam Rahima, 2016:28) Pemerolehan bahasa (language acquisition) adalah suatu proses yang dipergunakan anak-anak untuk menyesuaikan serangkaian hipotesis yang rumit, ataupun teori-teori yang masih terpendam atau tersembunyi dengan ucapan-ucapan orang tuanya sampai dia memilih, berdasarkan suatu ukuran atau takaran penilaian, tata bahasa yang paling baik serta yang paling sederhana dari bahasa tersebut.

Bahasa anak yang diperoleh anak adalah bahasa ibu, "bahasa ibu" bukan berarti bahasa ibunya dari anak tersebut. Boleh jadi misalnya seorang anak Indonesia yang mempunyai ibu dari suku Sunda atau Jawa kemudian sedari kecil dia diasuh oleh warga Negara Amerika, maka bahasa ibu anak tersebut bukanlah Jawa atau Sunda melainkan bahasa Inggris (Rahima, 2016:51).

Peristiwa-peristiwa dalam pemahaman kosakata dasar pada anak usia 3 tahun ini terjadi di sekiktar peneliti sendiri, khususnya di RT 24 Kelurahan Lebak Bandung Kecamatan lebak Bandung Kota Jambi, dengan kondisi ini peneliti tertarik untuk melakukan penelitian dengan judul "Pemerolehan Kosakata Dasar Nomina Bahasa Indonesia Anak Usia 3 (Studi Kasus di Kelurahan Lebak Bandung Kota Jambi)” Sesuai dengan latar belakang penelitian tersebut, fokus penelitian ini yaitu pemerolehan kosakata dasar nomina Bahasa Indonesia anak usia 3 (Studi Kasus di Kelurahan Lebak Bandung Kota Jambi)”. Penelitian ini dilakukan dengan memperhatikan kosakata yang telah dapat diucapkan dengan memperlihatkan gambar untuk memancing kosakata dasar nomina Bahasa Indonesia. Selain itu, penelitian ini juga berusaha menjawab pertanyaan bagaimana pemerolehan kosakata dasar nomina Bahasa Indonesia anak usia 3 (Studi Kasus di Kelurahan Lebak Bandung Kota Jambi)? Adapun tujuan penelitian yaitu mendeskripsikan pemerolehan kosakata dasar nomina Bahasa Indonesia pada anak usia 3 (Studi Kasus di Kelurahan Lebak Bandung Kota Jambi).

\section{Kajian Teori}

a. Pemerolehan Bahasa

Menurut Kiparsky (dalam Rahima, 2016:28) "Pemerolehan bahasa (language acquisition) adalah suatu proses yang dipergunakan anak-anak untuk menyesuaikan serangkaian hipotesis yang rumit, ataupun teori-teori yang masih terpendam atau tersembunyi dengan ucapan-ucapan orang tuanya sampai dia memilih, berdasarkan suatu ukuran atau takaran penilaian, tata bahasa yang paling baik serta yang paling sederhana dari bahasa tersebut. Senaada dengan hal tersebut, Rofii (2016) mengatakan bahwa Pemerolehan bahasa atau akuisisi bahasa adalah proses yang berlangsung di dalam otak kanak-kanak ketika dia memperoleh bahasa pertamanya atau bahasa ibunya. 


\section{b. Kosakata Dasar}

Menurut Soedjito (dalam Gustina, 2014) kosakata adalah (1) semua kata yang terdapat dalam satu bahasa; (2) kekayaan kata yang dimiliki oleh seorang pembicara; (3) kata yang dipakai dalam satu bidang ilmu pengetahuan; dan (4) daftar kata yang disusun seperti kamus disertai penjelasan secara singkat dan praktis.

c. Bahasa Indonesia

$$
\text { Dalam Wikipedia }
$$

(www.id.m.wikipedia.org) Bahasa

Indonesia adalah bentuk standar bahasa Melayu yang dijadikan sebagai bahasa resmi Republik Indonesia dan bahasa persatuan bangsa Indonesia. Bahasa Indonesia diresmikan penggunaannya setelah Proklamasi Kemerdekaan Indonesia, tepatnya sehari sesudahnya, bersamaan dengan mulai berlakunya konstitusi.

d. Anak

Menurut Lesmana (2012) secara umum dikatakan anak adalah seorang yang dilahirkan dari perkawinan antara seorang perempuan dengan seorang lakilaki dengan tidak menyangkut bahwa seseorang yang dilahirkan oleh wanita meskipun tidak pernah melakukan pernikahan tetap dikatakan anak

\section{e. Kata Dasar Nomina}

Menurut Hajar (dalam Budianto, 2016) nomina adalah kata yang mengacu pada manusia, benda, dan konsep atau pengertian (segi semantis). Dalam kalimat berpredikat verba, nomina menduduki fungsi subjek, objek atau pelengkap, nomina tidak dapat dijadikan bentuk ingkar tidak, tetapi dengan kata bukan. Contoh: Dokter, tambang, batang. Bagus dalam Budianto (2016) mengemukakan nomina (kata benda) adalah nama seseorang, tempat atau benda.

\section{METODE PENELITIAN}

Jenis penelitian ini adalah penelitian deskriptif kualitatif yaitu salah satu dari jenis penelitian yang termasuk dalam jenis penelitian kualitatif. Adapun tujuan dari penelitian ini adalah untuk mengungkapkan kejadian atau fakta, keadaan, fenomena, variabel dan keadaan yang terjadi saat penelitian berlangsung dengan menyuguhkan apa yang sebenarnya terjadi. Menurut Sukmadinata (2011), penelitian deskriptif kualitatif ditujukan untuk mendeskipsikan dan menggambakan fenomean-fenomena yang ada, baik bersifat alamiah maupun rekayasa manusia, yang lebih memperhatikan mengenai karakteristik, kualitas, keterkaitan atar kegiatan.

Menurut Nazir (dalam Futriana (2016)), metode deskriptif merupakan suatu metode dalam meneliti status sekelompok manusia, suatu objek, suatu set kondisi, suatu sistem pemikiran ataupun suatu kelas peristiwa pada masa sekarang. Tujuan dari penelitian deskriptif ini adalah untuk membuat deskripsi, gambaran, atau lukisan secara sistematis, faktual dan akurat mengenai fakta-fakta, sifat-sifat serta hubungan antarfenomena yang diselidiki.

Metode kualitatif merupakan cara yang digunakan peneliti untuk mendapatkan kata yang tertulis, ucapan dari seseorang, serta tingkah laku atau perbuatan objek yang akan diteliti. Metode kualitatif dalam penelitian ini akan menghasilkan data deskritif berupa kata-kata yang tertulis atau lisan dari orang-orang dan perilaku yang akan diamati (Bogman dan Taylor (dalam Moleong, 2012:4)).

Penelitian dalam studi kasus ini adalah untuk mendapatkan informasi tentang kemampuan pemerolehan kosakata anak usia 3 tahun. Subjek Penelitian akan diberikan simulasi 
tertentu yang nantinya akan diperhatikan rekasi subjek tersebut.

Adapun penelitian ini mengambil subjek penelitian berupa informan tunggal yang berusia tidak lebih dari tiga tahun yang tinggal di RT 24 Kelurahan Lebak Bandung Kota Jambi dengan persyaratan sebagai berikut ini:

a) Anak yang berusia tidak lebih dari 3 tahun.

b) Anak yang berdomisili di RT 24 Kelurahan Lebak Bandung.

c) Memiliki kelengkapan alat ucap. Objek penelitian ini adalah anak yang bernama Ziyan Ahya Pratama yang sudah sesuai dengan kriteria tersebut..

Dalam penelitian ini, Peneliti hanya menggunakan data primer. Menurut Subagyo (2015:87) data primer merupakan data yang diperoleh langsung dari masyarakat baik yang dilakukan melalui wawancara, observasi dan alat lainnya.

Data primer dalam penelitian ini berupa kata-kata yang diperoleh dari obyek penelitian yang bernama Ziyan. Data diambil berdasarkan tuturan kegiatannya sehari-hari.

Menurut Subagyo (2015, 104) analisis data dalam penelitian merupakan bagian dalam proses penelitian yang sangat penting karena dengan analisis inilah data yang ada akan nampak manfaatnya terutama dalam memecahkan masalah penelitian dan mencapai tujuan akhir penelitian. Tindakan yang dilakukan dalam penelitian ini adalah degan cara memperlihatkan gambar kepada anak untuk menjawab gambargambar yang diperlihatkan peneliti.

Langkah-langkah dalam analisis

data dilakukan sebagai berikut:

a) mengamati data yang telah dikumpulkan;

b) menganalisis data seuai dengan teori yang digunakan;

c) menentukan masing-masing data sesuai dengan bentuk-bentuk kosakata;

d) mendeksripsikan data yang telah dianalisis;

e) merumuskan kesimpulan.

\section{HASIL DAN PEMBAHASAN}

Berdasarkan hasil analisi yang telah laksanakan, maka diperoleh hasil pemerolehan kosakata dasar nomina anak usia 3 tahun, di Kelurahan Lebak Bandung Kota Jambi. Adapun kosakata dasar nomina yang dihasilkan oleh objek penelitian dapat dilihat pada tabel berikut.

Tabel 1. Data Pemerolehan Kosakata Dasar Nomina Bahasa Indonesia Anak Usia 3 Tahun (Informan: Ziyan)

\begin{tabular}{|c|c|c|c|c|}
\hline No. & $\begin{array}{c}\text { Kata } \\
\text { Nomina }\end{array}$ & Hasil Data & Hasil Analisis & Ket. \\
\hline 1. & Tas & $\begin{array}{l}\text { "Ini gambar apa, } \\
\text { Ziyan?" } \\
\text { "Ini Tas" }\end{array}$ & $\begin{array}{l}\text { Kata yang diperoleh adalah tas yang terdiri dari } 1 \\
\text { suku kata 'tas', merupakan kosakata dasar nomina } \\
\text { menurut teori yang dikemukakan oleh } \\
\text { Kridalaksana. }\end{array}$ & $\begin{array}{l}1 \text { suku } \\
\text { kata }\end{array}$ \\
\hline 2. & Motor & $\begin{array}{l}\text { "Ini gambar apa, } \\
\text { Ziyan?" } \\
\text { "Ini motol balap” (Ini } \\
\text { motor balap) }\end{array}$ & $\begin{array}{l}\text { Kata yang diperoleh adalah motol (motor) yang } \\
\text { terdiri dari } 2 \text { suku kata 'mo-tor', merupakan } \\
\text { kosakata dasar nomina menurut teori di bab II } \\
\text { sesuai dengan teori yang dikemukakan oleh } \\
\text { Kridalaksana. }\end{array}$ & $\begin{array}{l}2 \text { suku } \\
\text { kata }\end{array}$ \\
\hline 3. & Gitar & “Ini apa, Ziyan?” & $\begin{array}{l}\text { Kata yang diperoleh adalah gital (gitar) yang terdiri } \\
\text { dari } 2 \text { suku kata, 'gi-tar', merupakan kosakata }\end{array}$ & $\begin{array}{l}2 \text { suku } \\
\text { kata }\end{array}$ \\
\hline
\end{tabular}




\begin{tabular}{|c|c|c|c|c|}
\hline & & $\begin{array}{l}\text { "Ini gital” } \\
\text { (Ini gitar) }\end{array}$ & $\begin{array}{l}\text { dasar nomina menurut teori yang dikemukakan oleh } \\
\text { Kridalaksana. }\end{array}$ & \\
\hline 4. & $\begin{array}{l}\text { Bola } \\
\text { (Kecil) }\end{array}$ & “Ini apa Ziyan?” & $\begin{array}{l}\text { Kata yang diperoleh adalah bola yang terdiri dari } 2 \\
\text { suku kata 'bo-la', merupakan kosakata dasar } \\
\text { nomina menurut teori yang dikemukakan oleh } \\
\text { Kridalaksana }\end{array}$ & $\begin{array}{l}2 \text { suku } \\
\text { kata }\end{array}$ \\
\hline 5. & Air Teh & “Ziyan minum apa?” & $\begin{array}{l}\text { Kata yang diperoleh adalah ai teh yang terdiri dari } \\
2 \text { suku kata 'ai-teh', merupakan kosakata dasar } \\
\text { nomina menurut teori yang dikemukakan oleh } \\
\text { Kridalaksana. }\end{array}$ & $\begin{array}{l}2 \text { suku } \\
\text { kata }\end{array}$ \\
\hline 6. & Pedang & “Ini apa, Ziyan?” & $\begin{array}{l}\text { Kata yang diperoleh adalah pedang yang terdiri } \\
\text { dari } 2 \text { suku kata 'pe-dang', merupakan kosakata } \\
\text { dasar nomina menurut teori yang dikemukakan oleh } \\
\text { Kridalaksana. }\end{array}$ & $\begin{array}{l}2 \text { suku } \\
\text { kata }\end{array}$ \\
\hline 7. & Baju & $\begin{array}{l}\text { "Ini gambar apa, } \\
\text { Ziyan?" } \\
\text { "Baju” }\end{array}$ & $\begin{array}{l}\text { Kata yang diperoleh adalah baju yang terdiri dari } 2 \\
\text { suku kata 'ba-ju', merupakan kosakata dasar } \\
\text { nomina menurut teori yang dikemukakan oleh } \\
\text { Kridalaksana. }\end{array}$ & $\begin{array}{l}2 \text { suku } \\
\text { kata }\end{array}$ \\
\hline 8. & Sendok & $\begin{array}{l}\text { "Ini gambar apa, } \\
\text { Ziyan? } \\
\text { "cendok" }\end{array}$ & $\begin{array}{l}\text { Kata yang diperoleh adalah sendok yang terdiri } \\
\text { dari } 2 \text { suku kata 'sen-dok', merupakan kosakata } \\
\text { dasar nomina menurut teori yang dikemukakan oleh } \\
\text { Kridalaksana. }\end{array}$ & $\begin{array}{l}2 \text { suku } \\
\text { kata }\end{array}$ \\
\hline 9. & Es Krim & “Ziyan makan apa? & $\begin{array}{l}\text { Kata yang diperoleh adalah es krim terdiri dari } 2 \\
\text { suku kata 'es-krim', merupakan kosakata nomina } \\
\text { turunan sesuai dengan pendapat yang dikemukakan } \\
\text { oleh Rahman. }\end{array}$ & $\begin{array}{l}2 \text { suku } \\
\text { kata }\end{array}$ \\
\hline 10. & Piring & $\begin{array}{l}\text { "Ini gambar apa, } \\
\text { Ziyan?”" (piring) } \\
\text { "Piling” }\end{array}$ & $\begin{array}{l}\text { Kata yang diperoleh adalah piring yang terdiri dari } \\
2 \text { suku kata 'pi-ring', merupakan kosakata nomina } \\
\text { dasar sesuai yang dikemukakan oleh Kridalaksana. }\end{array}$ & $\begin{array}{l}2 \text { suku } \\
\text { kata }\end{array}$ \\
\hline 11. & Mobil & $\begin{array}{l}\text { "Ini gambar apa, } \\
\text { Ziyan?" } \\
\text { "Mobil" }\end{array}$ & $\begin{array}{l}\text { Kata yang diperoleh mobil yang terdiri dari } 2 \text { suku } \\
\text { kata 'mo-bil', merupakan kosakata nomina dasar } \\
\text { sesuai yang dikemukakan oleh Kridalaksana. }\end{array}$ & $\begin{array}{l}2 \text { suku } \\
\text { kata }\end{array}$ \\
\hline & Buku & $\begin{array}{l}\text { "Ini gambar apa, } \\
\text { Ziyan?”" } \\
\text { "Ini buku” }\end{array}$ & $\begin{array}{l}\text { Kata yang diperoleh adalah buku yang terdiri dari } 2 \\
\text { suku kata 'bu-ku', merupakan kosakata nomina } \\
\text { dasar sesuai dengan yang dikemukakan oleh } \\
\text { Kridalaksana. }\end{array}$ & $\begin{array}{l}2 \text { suku } \\
\text { kata }\end{array}$ \\
\hline & Pena & $\begin{array}{l}\text { "Ini gambar } \\
\text { apa,Ziyan?” gena” }\end{array}$ & $\begin{array}{l}\text { Kata yang diperoleh adalah pena yang terdiri dari } 2 \\
\text { suku kata 'pe-na', merupakan kosakata nomina } \\
\text { dasar sesuai dengan yang dikemukakan oleh } \\
\text { Kridalaksana. }\end{array}$ & $\begin{array}{l}2 \text { suku } \\
\text { kata }\end{array}$ \\
\hline & Televisi & $\begin{array}{l}\text { "Ini gambar apa, } \\
\text { Ziyan?”" } \\
\text { “Tipi” (Televisi) }\end{array}$ & $\begin{array}{l}\text { Kata yang diperoleh adalah tivi yang terdiri dari } 2 \\
\text { suku kata 'ti-vi', merupakan kosakata nomina dasar } \\
\text { sesuai dengan yang dikemukakan oleh } \\
\text { Kridalaksana. }\end{array}$ & $\begin{array}{l}2 \text { suku } \\
\text { kata }\end{array}$ \\
\hline & $\begin{array}{l}\text { Kompang } \\
\text { an }\end{array}$ & $\begin{array}{l}\text { 'Tompanan' } \\
\text { (Kompangan) }\end{array}$ & $\begin{array}{l}\text { Kata yang diperoleh adalah tompanan } \\
\text { (kompangan) yang terdiri dari } 3 \text { suku kata 'kom- } \\
\text { pa-ngan', merupakan kosakata dasar nomina } \\
\text { menurut teori yang dikemukakan oleh } \\
\text { Kridalaksana. }\end{array}$ & $\begin{array}{l}3 \text { suku } \\
\text { kata }\end{array}$ \\
\hline & Sepatu & gambar & Kata yang diperoleh adalah sepatu yang terdiri dari & 3 suku \\
\hline
\end{tabular}




\begin{tabular}{|c|c|c|c|c|}
\hline & & $\begin{array}{l}\text { Ziyan?” } \\
\text { “tepatu” (sepatu) }\end{array}$ & $\begin{array}{l}3 \text { suku kata 'se-pa-tu', merupakan kosakata dasar } \\
\text { nomina menurut teori yang dikemukakan oleh } \\
\text { Kridalaksana. }\end{array}$ & kata \\
\hline 17. & Sepeda & $\begin{array}{l}\text { "Ini gambar apa, } \\
\text { Ziyan?”" } \\
\text { “Cepeda” (sepeda) }\end{array}$ & $\begin{array}{l}\text { Kata yang diperoleh adalah sepeda yang terdiri dari } \\
3 \text { suku kata 'se-pe-da', merupakan kosakata dasar } \\
\text { nomina menurut teori yang dikemukakan oleh } \\
\text { Kridalaksana. }\end{array}$ & $\begin{array}{l}3 \text { suku } \\
\text { kata } \\
3\end{array}$ \\
\hline 18. & Helikopter & $\begin{array}{l}\text { "Ini gambar apa, } \\
\text { Ziyan?” } \\
\text { "Helikoptel” } \\
\text { (helikopter) }\end{array}$ & $\begin{array}{l}\text { Kata yang diperoleh adalah helikoptel (helikopter) } \\
\text { yang terdiri dari } 4 \text { suku kata 'he-li-kop-ter', } \\
\text { merupakan kosakata dasar nomina menurut teori di } \\
\text { bab II sesuai dengan teori yang dikemukakan oleh } \\
\text { Kridalaksana. }\end{array}$ & $\begin{array}{l}4 \text { suku } \\
\text { kata }\end{array}$ \\
\hline 19. & $\begin{array}{l}\text { Bola } \\
\text { (Besar) }\end{array}$ & "Ini apa ya Ziyan”? & $\begin{array}{l}\text { Kata yang diperoleh adalah adalah yang terdiri dari } \\
4 \text { suku kata "ten-dang-ka-ki", merupakan kosakata } \\
\text { dasar nomina, yang berbentuk nomina turunan } \\
\text { sesuai dengan teori yang dikemukakan oleh } \\
\text { Rahman. }\end{array}$ & $\begin{array}{l}4 \text { suku } \\
\text { kata }\end{array}$ \\
\hline 20. & Foto Ayah & $\begin{array}{l}\text { "Ini foto siapa Ziyan?" } \\
\text { "Poto Ayah" }\end{array}$ & $\begin{array}{l}\text { Kata yang diperoleh Foto Ayah yang terdiri dari } 4 \\
\text { suku kata 'po-to-a-yah', merupakan kosakata } \\
\text { nomina turunan sesuai dengan pendapat yang } \\
\text { dikemukakan oleh Rahman. }\end{array}$ & $\begin{array}{l}4 \text { suku } \\
\text { kata }\end{array}$ \\
\hline & $\begin{array}{l}\text { Baju } \\
\text { Doraemon }\end{array}$ & $\begin{array}{l}\text { "Ini apa namanya } \\
\text { Ziyan?" } \\
\text { "Baju dolaemon” }\end{array}$ & $\begin{array}{l}\text { Kata yang diperoleh baju doraemon yang terdiri } \\
\text { dari } 6 \text { suku kata 'ba-ju-do-ra-e-mon', merupakan } \\
\text { kosakata nomina turunan, sesuai yang dikemukakan } \\
\text { oleh Rahman. }\end{array}$ & $\begin{array}{l}6 \text { suku } \\
\text { kata }\end{array}$ \\
\hline
\end{tabular}

Data (1) sampai data (21) merupakan tuturan dari seorang anak yang berusia 3 tahun. Tujuan komunikasi ini adalah mengetahui sejauh mana kemampuan informan dalam menyebutkan kosakata terhadap benda yang dilihat dan dipegangnya. Pada konteks percakapan data ini informan sudah mengetahui apa nama benda dalam gambar yang dilihatnya dan kata kerja yang sedang dikerjakan.

Pada umumnya Informan hanya memberikan informasi hanya dalam satu kata dan dua kata untuk menerangkan kata benda yang dilihatnya dan kata kerja yang dililhatnya dan dikerjakannya. Suku kata yang mampu diucapkan oleh Informan adalah sebanyak 2-3 suku kata, bahkan ada yang sampai 6 suku kata.

\section{SIMPULAN}

Berdasarkan hasil dan pembahasan yang telah dilakukan, maka dapat disimpulkan bahwa informan (Ziyan) belum terlalu banyak menguasai kosakata khusus kata dasar nomina yang dituturkan secara lengkap. Ziyan telah memperoleh berbagai macam kosakata dasar nomina yang terdiri dari satu suku kata, dua suku kata, tiga suku kata, empat suku kata, dan enam suku kata mampu diucapkan walaupun pengucapan tidak sempurna dan diucapkan dengan kata-katanya sendiri.

\section{DAFTAR PUSTAKA}

Budianto. (2016). Kata Benda (Nomina)-Pengertian, Ciri, Jenis, dan Contohnya. http://www.artikelmateri.com/201 
6/11/kata-benda-nominapengertian-ciri-jenis-contohnyaadalah.html Diakses tanggal 23 Oktober 2017 Pukul 19.35 WIB

Futriana, Merlita. (2016). Metodologi Penelitian - Wawancara. http://merlitafutriana0.blogspot.co m/p/wawancara.html. Diakses pada tanggal 18 November 2018. Pukul 15.12 WIB

Gustina, Mira. Pengertian (2014). kosakata Menurut Para Ahli. https://miragustina90.blogspot.co m/2014/03/pengertian-kosakatamenurut-para-ahli.html Diakses tanggal 25 Oktober 2017. Pukul 20.00 WIB

Kridalaksana. (1992). Pembentukan Kata Dalam Bahasa Indonesia. Jakarta. PT. Gramedia

Lesmana, Andi. Definisi Anak. (2017) https://andibooks.wordpress.com/ definisi-anak/ diakses tanggal 23 Oktober 2017 pukul 19.25.

Moleong, Lexy J. (2012). Metodologi Penelitian Kualitatif. Bandung. PT. Remaja Rosdakarya.
Rahima, Ade. (2016). Dasar-Dasar Psikolinguistik: Suatu Tinjauan Psikologi Bahasa. Jambi: Unbari press

Rahman,

Arif. (2018) www.ilmudasar.com diakses tanggal 23 Oktober 2018 pada pukul 10.11 WIB.

Rofii, Afif. (2016) An Analysis of Syntactical Ability of Second Language Children Age 5-6 Years Old in Taman Kanak-Kanak (TK) Para Bintang Kota Jambi. Jurnal Ilmiah Dikdaya, Vol. 06, Nomor 1

2016.http://dikdaya.unbari.ac.id/i ndex.php/dikdaya/article/view/38

Subagyo, Joko. (2015). Metode Penelitian Dalam Teori dan Pratik. Jakarta: Rineka Cipta.

Sukmadinata, Nana Syaodih. (2011). Metodi Penelitian Pendidikan. Bandung. PT. Remaja Rosdakarya. www.wikipedia.org. Diakses tanggal 23 Oktober 2017 Pukul 19.30

WIB. 